\begin{tabular}{c} 
JCEBT, 2 (1) Maret $2018 \quad$ ISSN 2549-6379 (Print) ISSN 2549-6387 (Online) \\
JCEBT \\
OEournal of Civil Engineering, Building and Transportation) \\
Available online http://ojs.uma.ac.id/index.php/jcebt \\
\hline
\end{tabular}

\title{
Optimasi Biaya Dan Waktu Akibat Penjadwalan Ulang Pada Proyek Perumahan Menggunakan Microsoft Project
}

\section{Optimization Of Cost And Time Due To Scheduling In Housing Projects Using Microsoft Project}

\author{
Sopian Tamba, Deni Maisandi Hutauruk \\ Program Studi Teknik Sipil Fakultas Teknik \\ Universitas Medan Area, Indonesia \\ E-mail:Tambasopian1@yahoo.co.id
}

\begin{abstract}
Abstrak
Penjadwalan ulang ini dilakukan menggunakan program komputer microsoft project untuk mendapat kan hasil yang lebih efisien dan efektif, Dengan durasi yang optimal. Dalam penjadwalan proyek ini menggunakan metode jaringan kerja PDM (precedence diagram method) metode dengan satu garis dari pekerjaan terdahulu ke pekerjaan berikutnya satu konstrain hanya dapat menghubungkan dua pekerjaan. karena setiap node memiliki dua ujung awal (S) dan akhir (F) maka ada empat macam konstrain. SS, SF, FS, FF. Dengan penjadwalan kembali proyek ini menggunakan metode PDM pada microsoft project dan penambahan sumber daya, maka di dapat hasil durasi lebih optimal, biaya langsung bertambah dan biaya tidak langsung berkurang. Dengan hasil sebagai beikut optimasi biaya sebesar Rp. 40.987 .500 optimasi waktu sebanyak 15 hari dengan total biaya awal proyek sebesar Rp 1.757.551.500,- setelah penjadwalan ulang berkurang menjadi sebesar Rp 1.716.569.000,-

Kata Kunci : Proyek konstruksi, microsoft project, metode PDM, Optimal
\end{abstract}

\begin{abstract}
Abstract This rescheduling is done using a microsoft project computer program to get more efficient and effective results, with optimal duration. In the scheduling of this project using the PDM network method (precedence diagram method) method with a line from previous work to the next job one constraint can only connect two jobs.Since each node has two initial ends $(S)$ and end $(F)$ then there are four kinds of constraints. SS, SF, FS, FF. With the rescheduling of this project using the PDM method on microsoft project and the addition of resources, then in the results can be more optimal duration, direct costs increase and indirect costs are reduced.
\end{abstract}

Key word: Construction project, Controlling, Earned value analysis, optimal 


\section{PENDAHULUAN}

Demi kelancaran jalannya sebuah proyek dibutuhkan manajemen yang akan mengelola proyek dari awal hingga proyek berakhir, yakni manajemen proyek. Bidang manajemen proyek tumbuh dan berkembang karena adanya kebutuhan dalam dunia industri modern untuk mengkoordinasi dan mengendalikan berbagai kegiatan yang semakin kompleks. Manajemen proyek mempunyai sifat istimewa, dimana waktu kerja manajemen dibatasi oleh jadwal yang telah ditentukan (Hartawan, n.d). Perubahan kondisi yang begitu cepat menuntut setiap pimpinan yang terlibat dalam proyek untuk dapat mengantisipasi keadaan, serta menyusun bentuk tindakan yang diperlukan. Hal ini dapat dilakukan bila ada konsep perencanaan yang matang dan didasarkan pada data, informasi, kemampuan, dan pengalaman.Keberhasilan ataupun kegagalan dari pelaksanaan seringkali disebabkan kurang terencananya kegiatan proyek serta pengendalian yang kurang efektif. Sehingga kegiatan proyek tidak efisien, hal ini akan mengakibatkan keterlambatan, menurunnya kualitas pekerjaan, dan memperbesar biaya pelaksanaan. Keterlambatan penyelesaian proyek sendiri adalah kondisi yang sangat tidak dikehendaki. Maksud dari penelitian ini adalah penjadwalan ulang pekerjaan dengan membuat jaringan kerja berbasis microsoft project tujuan untuk menghasilkan waktu dan biaya yang optimal Dalam pelaksanaan suatu proyek sangat jarang ditemui suatu proyek yang berjalan tepat sesuai dengan yang direncanakan, umumnya mengalami keterlambatan dariyang direncanakan, baik waktu maupun kemajuan pekerjaan, tetapi ada juga proyekyang mengalami percepatan dari jadwal awal yang direncanakan. Untuk menghindari kerugiaan dalam proyek, kita dapat meramalkan (forecasting) terhadap biayapenyelesaian dengan konsep nilai hasil (earned value analysis) (Irfanur Rahman,2010). Pengendalian biaya merupakan hal penting dalam setiap proyek konstruksi. Pengendalian biaya tidak hanya memonitor biaya dan mencatat data kuantitas saja,tetapi juga menganalisis data untuk melakukan tindakan koreksi sebelum terlambat.Manajemen yang efektif dari suatu program selama siklus operasi proyek konstruksi, memerlukan pengorganisasian biaya dan sistem pengontrolan yang baik. Manajemen harus membandingkan biaya, waktu dan kinerja dari program terhadap rencana penganggaran biaya, waktu dan kinerja secara simultan dan terintegrasi dalam setiap aktifitas (Herry P. Chandra, et al, 
2004) Pemantauan dan pengendalian pelaksanaan proyek dilakukan dengan tujuan untuk mengetahui laju pelaksanaan pekerjaan, sehingga penyimpanganpenyimpangan yang terjadi dapat dengan cepat diketahui dan dapat dilakukan langkah-langkah penanganan yang sesuai. Dalam pelaksanaanya diperlukan teknikteknik, metode dan bahkan alat bantu yang dapat mempermudah dalam pelaksanaannya baik berupa tabel, grafik ataupun program aplikasi. Alat bantu yang dipergunakan dalam pelaksanaan pemantauan dan pengendalian pelaksanaan proyek konstruksi harus mudah dipergunakan, mudah dibaca dan aplikatif (Tridjoko Sri Margianto \& Heri Suprapto, 2006). Berdasarkan survei dinyatakan bahwa Microsoft Project merupakan suatu alat bantu atau tools yang menduduki peringkat pertama sebagai alat bantu dalam mendukung manajemen proyek. Hal ini merupakan implikasi dari kehandalan software aplikasi tersebut menangani manajemen proyek (Catur Bawa, 2007).Konsep "earned value" merupakan salah satu alat yang digunakan dalam pengelolaan proyek yang mengintegrasikan biaya dan waktu. Konsep earned value menyajikan tiga dimensi yaitu penyelesaian fisik dari proyek (the percent complete) yang mencerminkan rencana penyerapan biaya (budgeted cost), biaya aktual yang sudah dikeluarkan atau yang disebut dengan actual cost serta apa yang yang didapatkan dari biaya yang sudah dikeluarkan atau yang disebut earned value. Dari ketiga dimensi tersebut, dengan konsep earned value, dapat dihubungkan antara kinerja biaya dengan waktu yang berasal dari perhitungan varian dari biaya dan waktu (Flemming dan Koppelman, 1994) dalam makalah Biemo W. Sumardi et al Pengendalian biaya merupakan hal penting dalam setiap proyek konstruksi. Pengendalian biaya tidak hanya memonitor biaya dan mencatat data kuantitas saja,tetapi juga menganalisis data untuk melakukan tindakan koreksi sebelum terlambat.Manajemen yang efektif dari suatu program selama siklus operasi proyek konstruksi, memerlukan pengorganisasian biaya dan sistem pengontrolan yang baik. Manajemen harus membandingkan biaya, waktu dan kinerja dari program terhadap rencana penganggaran biaya, waktu dan kinerja secara simultan dan terintegrasi dalam setiap aktifitas. Microsoft Project

Microsoft project Pengertian microsoft project 2007 (MSP atau Winproj) adalah suatu manajemen proyek perangkat lunak program yang dikembangkan dan dijual oleh microsoft yang dirancang untuk membantu manajer 
proyek dalam mengembangkan rencana, menetapkan sumber daya untuk tugastugas pelacakan kemajuan, pengelola anggaran dan menganalisis beban kerja. Microsoft Project 2007 adalah sebuah aplikasi untuk mengelola suatu proyek. Microsoft project merupakan sistem perencanaaan yang dapat membantu dalam menyusun penjadwalan (scheduling) suatu proyek atau rangkaian pekerjaan. Microsoft project juga mampu membantu melakukan pencatatan dan pemantauan terhadap penggunaan sumber daya (resource), baik yang berupa sumber daya manusia maupun yang berupa peralatan. Yang dikerjakan oleh microsoft project antara lain: mencatat kebutuhan tenaga kerja pada setiap sektor, mencatat jam kerja para pegawai, jam lembur dan menghitung pengeluaran sehubungan dengan ongko tenaga kerja, memasukkan biaya tetap, menghitung total biaya proyek, serta membantu mengontrol penggunaan tenaga kerja pada beberapa pekerjaan untuk menghindari overallocation (kelebihan beban pada penggunaan tanga kerja) (Adi Kusrianto, 2008).

Iman Soeharto (1995), di dalam proses mencapai tujuan tersebut telah ditentukan batasan yaitu besar biaya (anggaran) yang dialokasikan, dan jadwal serta mutu yang harus dipenuhi. Ketiga batasan di atas disebut tiga kendala (triple constraint). Seperti diperlihatkan oleh Gambar 2.1 ini merupakan parameter penting bagi penyelenggaran proyek yang sering diasosiasikan sebagai sasaran proyek Jadwal waktu proyek merupakan alat yang dapat menunjukkan kapan berlangsungnya setiap kegiatan, sehingga dapat digunakan pada waktu merencanakan kegiatan kegiatan maupun untuk pengendalian pelaksanaan proyek secara keseluruhan. Jadwal pelaksanaan proyek berguna untuk menentukan waktu dan urutan kegiatanproyek dan dibuat berdasarkan daftar perincian pekerjaan. Rencana kerja dan jadwal waktu proyek merupakan tulang punggung keseluruhan proses konstruksi, sehingga harus dibuat berdasarkan pada sasaran dan pencapaian target yang jelas dengan memakai jadwal rencana kerja yang tepat sumber daya yang memadai dapat tersedia pada saat yang tepat, setiap tahap proses mendapatkan alokasi waktu cukup dengan berbagai kegiatan dapat dimulai pada saat yang tepat pula. Dalam menyusun jadwal rencana kerja harus sudah mempertimbangkan dan mencakup : 1.estimasi kebutuhan sumber daya dan dana disertai dengan analisis penggunaannya yang paling mangkus, dan 2. menentukan rambu-rambu pengukuran target kemajuan proyek (Istimawan 
Dipohusodo, 1996) biaya aktual yang dikeluarkan untuk penyelesaian pekerjaan pada periode waktu yang bersangkutan. Biaya aktual didapat dari laporan-laporan dan dikumpulkan pada level cost account periode itu. Indikator-indikator konsep nilai hasil ini kemudian dapat dibuat grafik berbentuk huruf "S", sehingga akan segera terlihat jika terjadi penyimpangan. Jadwal waktu proyek merupakan alat yang dapat menunjukkan kapan berlangsungnya setiap kegiatan, sehingga dapat digunakan pada waktu merencanakan kegiatan kegiatan maupun untuk pengendalian pelaksanaan proyek secara keseluruhan. Jadwal pelaksanaan proyek berguna untuk menentukan waktu dan urutan kegiatankegiatan proyek dan dibuat berdasarkan daftar perincian pekerjaan. Rencana kerja dan jadwal waktu proyek merupakan tulang punggung keseluruhan proses konstruksi, sehingga harus dibuat berdasarkan pada sasaran dan pencapaian target yang jelas dengan memakai jadwal rencana kerja yang tepat sumber daya yang memadai dapat tersedia pada saat yang tepat, setiap tahap proses mendapatkan alokasi waktu cukup dengan berbagai kegiatan dapat dimulai pada saat yang tepat pula. Dalam menyusun jadwal rencana kerja harus sudah mempertimbangkan dan mencakup 1.estimasi kebutuhan sumber daya dan dana disertai dengan analisis penggunaannya yang paling mangkus, dan 2. menentukan rambu-rambu pengukuran target kemajuan proyek (Istimawan Dipohusodo, 1996)

\section{METODE PENELITIAN}

Metode yang digunakan dalam penelitian ini adalah metode analisis deskriptif, yaitu metode untuk memecahkan suatu masalah yang ada dengan cara mengumpulkan data, disusun, dijelaskan, diolah dan dianalisis sehingga diperoleh hasil akhir. Hasil akhir ini kemudian digunakan sebagai bahan untuk mengambil kesimpulan dari pemasalahan yang ada. Pada penelitian ini, konsep nilai hasil digunakan sebagai metode pengendalian biaya dan jadwal yang memperhatikan kinerja proyek. Adapun analisis konsep nilai hasil ini dilakukan dengan bantuan program Microsoft Project

\section{Data Primer}

Data primer sebagai berikut: Rencana Anggaran Biaya (RAB), Daftar harga satuan bahan, alat dan upah tenaga kerja, Time schedule atau kurva S, Laporan mingguan yang berisi kemajuan proyek, Daftar penggunaan bahan, alat dan tenaga kerja per 1 Unit rumah

\section{Data Sekunder}

Data sekunder dari proyek sisuka residence adalah: sumber daya (sdm) /tenaga kerja, data pengadaan atau 
kebutuhan material di lapangan datadata proyek Lokasi Proyek : Desa Sei suka Kec.Seisuka Kab Batubara Jenis Proyek : Proyek Pembanguan Perumahan Waktu Proyek : Start Agustus 2016 S/D Selesai

Pemilik Proyek : PT. Kharisma Abadi Mega Indah (KAMI)

Precedent Diagram Method (PDM) merupakan hubungan keterkaitan antara satu pekerjaan dengan pekerjaan lain. Dalam Microsoft Project mengenal 4 macam hubungan antar pekerjaan, yaitu:

1. FS (Finish to Start) Suatu pekerjaan baru boleh dimulai jika pekerjaan yang lain selesai.

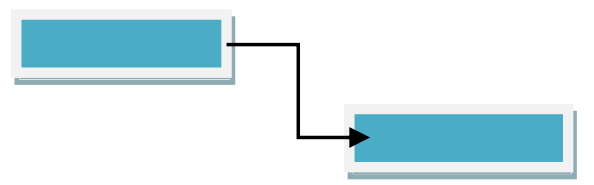

Gambar 1 : konstrain FS

Sumber : program microsoft project

2. FF (Finish To Finish) Suatu pekerjaan harus selesai bersamaan dengan selesainya pekerjaan lain.

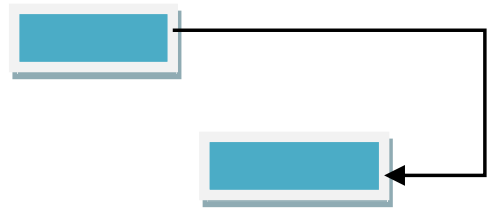

Gambar 2 : konstrain FF

Sumber: program microsoft project

3. SS (Start to Start) Suatu pekerjaan harus simulai bersamaan dengan pekerjaan lain.

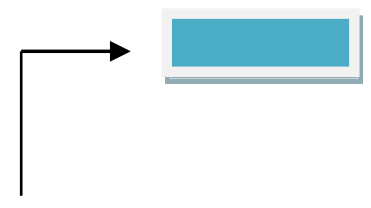

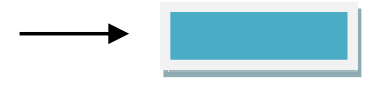

Gambar 3. Konstrain SS

Sumber : Program microsoft project

4. SF (Start to Finish) Suatu pekerjaan baru boleh diakhiri jika pekerjaan lain dimulai.

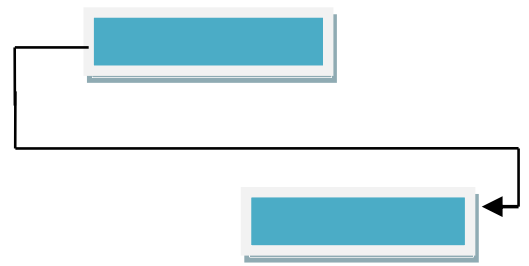

Gambar 4 . konstrain SF

Sumber : Program microsoft project

Lokasi Penelitian Proyek ini terletak di Desa Sei Suka Kecamatan Seisuka Kabupaten Batubara Sumatera Utara. Beberap hal penting yang berhubungan dengan pelaksanaan pekerjaa pada proyek ini adalah sebagai berikut : Kemampuan dari seorang project manejer berdasarkan pengalaman yang sudah dilalui yang mampu menganalisis item pekerjaan yang mengalami kritis sehingga bisa di prioritas kan sebagai percepatan durasi yang menghasilkan waktu dan biaya yang optimal

\section{HASIL DAN PEMBAHASAN}

Proyek pembangunan perumahan Sei Suka Residence menggunakan program microsoft project 2007. Dan analisa Standart analisa indonesisa (SNI. Pada microsoft project ini Analisis data dilakukan langsung dengan menginput data secara langsung ke dalam program 
microsoft project 2007 yang meliputi dua tahap yaitu

a. Menyusun rencana jadwal dan biaya proyek (baseline)

b. Aktualiasasi di lapangan (tracking)

Penjadwalan dan Estmiasi Biaya dengan Standar Nasioanal Indonesia (SNI) pada pelaksaan preoyek perumahan seisuka residence batubara menggunakan standar nasional indonesi (SNI) untuk estimasi biaya dan penjadwalan proyek.

Estimasi Biaya

Estimasi perencanaan biaya digunakan dengan metode SNI dimana ini merupakan rencana biaya menggunakan standar nasioanal indonesia (SNI) yang disebut sebagai rencana anggaran biaya (RAB) dengan hasil sebagai berikut

Biaya langsung

Analisa SNI

Rp. $1,795,447,203.69$

PPN $10 \%$ Rp. $179,544,702.37$

Biaya Tidak Langsung

Tidak langsun

Rp. 262500,000.00

Total

Rp. 2,237,491,924.05

Penjadwalan

Proyek

(Time

Scheduling)

Penjadwalan proyek perumahan Sei Suka Residence dengan standar nasional indonesia Menggunakan aplikasi microsoft excel dengan total waktu pengerjaan 5 bulan (24 minggu)

Analisis Biaya Dengan Microsoft Project

\section{Biaya tidak langsung}

Biaya tidak langsung didapat Rp.

262.000.000

Harga jadwal awal J1 = Rp 262.500.000,Harga jadwal ulang J2 = Rp 214,671,000,-

Biaya langsung merupakan harga baku.

Harga total biaya $\mathrm{P} 1=\mathrm{Rp} 1,757,551,500$

\section{SIMPULAN}

Hasil perhitungan kompresi terhadap jaringan kerja pada pembangunan proyek perumahan SEI SUKA RESIDENCE BATUBARA, maka dapat diambil kesimpulan yaitu. Setelah melakukan penjadwalan ulang pada durasi kegiatan normal proyek, maka diketahui durasi kegiatan normal 100 hari menjadi 85 hari dengan penurunan biaya sebesar Rp 40,987,500.,- dan jumlah SDM pada pekerjaan yang dipercepat menjadi bertambah $8 \%$ dengan pertambahan biaya langsung sebesar $\mathrm{Rp} 6,841,500$ .Dari kesimpulan di atas dapat diketahui, semakin dipercepat durasi penyelesaiannya maka jumlah SDM yang dibutuhkan semakin meningkat. Dari segi biaya proyek, biaya langsungnya akan mengalami kenaikan yang diakibatkan oleh bertambahnya pekerja, tetapi seiring dengan berkurangnya durasi proyek, menyebabkan biaya tidak langsungnya juga mengalami penurunan. Dengan hasil akhir sebagai berikut 
Selisih Biaya langsung $=\operatorname{Rp} 6,841,500$

Selisih biaya tidak langsung $=\mathrm{Rp}$

$47,829,000$

Optimasi biaya sebesar Rp.

40.987.500 Optimasi waktu sebanyak 15

hari Dengan total biaya awal proyek

sebesar Rp 1.757.551.500,- setelah

penjadwalan ulang berkurang menjadi

sebesar Rp 1.716.569.000,-.

\section{DAFTAR PUSTAKA}

Chandra, Herry. P et.al 2004 pengendalian pelaksanaan konstruksi berdasarkan konsep nilai hasil pada pembanguna pabrik $\mathrm{x}$ di gresik Uk Petra.

Dipohusodo, Istimawan. 1996. Manajemen proyek dan konstruksi. Kanisius. Jakarata

Fleming. Q.W \& koppelman, j.m (1994) the esense and evolution of earned value. Transaction of AACE internationl. 1994

Husen, A. 2009. Manajemen proyek: perencanaan penjadwlan pengendalian proyek. Yogyakarta: Andi

Kusrianto, adi. 2008. Panduan lengkap memakai microsoft 2007. Jakarta: PT. Alex Media Komputindo

Rahman, irfanur. 2010 earned value jhkdjkjfanalysis terhadap waktu pada proyek pembangunan gedung. Skripsi, jurusan teknik sipil fakultas teknik universitas sebelas maret surakarta.

Soeharto, Iman. 2001. Manajemen proyek dari konseptual sampai operasional. Jakarta: Erlangga 